Environment Conservation Journal 14(3) 109-111, 2013

ISSN 0972-3099 (Print) 2278-5124 (Online)

Abstracted and Indexed

\title{
Stegodyphus semadohensis: A new species from family Eresidae, recorded from Satpuda, Maharashtra, India (Arachnida: Araneae: Eresidae)
}

\section{Deshmukh Ujjwala Shivaji}

Received: 15.12 .2012
Revised: 13.04.2013
Accepted: 05.6.2013

\begin{abstract}
Eresidae are represented poorly in Indian fauna. All over the world about hundred species in ten genera are known and about 29 species have been studied under the genus Stegodyphus. The genus Stegodyphus was established by Simon 1873, with the type species $S$. lineatus Latneille. Pocock (1900) described five species of Stegodyphus. Tikader (1963) illustrated Pococks Stegodyphus pacificus socialis for easy identification. Gajbe (2007) redescribed and reillustrated Stegodyphus sarasinorum Karsch including male. The study examines species in a relatively diverse lineage of genus Stegodyphus, where they undergone adaptive radiation. One new species of spider from family Eresidae, genus Stegodyphus (Stegodyphus semadohensis sp. nov. female) is recorded from Satpuda (Maharashtra State) India, during 2009.
\end{abstract}

Keywords: Spiders, Eresidae, Stegodyphus semadohensis

\section{Introduction}

Eresids are commonly called as velvet spiders or social spiders. Eresidae are a small group (about 100 species in 10 genera) of almost totally old World. About 29 species have been studied under the genus Stegodyphus. The characteristics of this family of spiders are that they are entelegyne (have a genital plate in the female), eight-eyed, araneomorph spiders that build unkempt webs and are also characterized by their short, stout bodies, which are usually covered with fine hairs and pubescence. The spiders of this genus occur on bushes, branches of trees and fencings, with large sheet like or sac like web. The spiders of the family Eresidae are represented poorly in India. The genus Stegodyphus was established, with the type species $S$. lineatus Latneille. Pocock (1900) described five species of Stegodyphus. Tikader (1963) illustrated Pococks Stegodyphus pacificus socialis for easy identification. Gajbe (2007) redescribed and reillustrated Stegodyphus sarasinorum Karsch including male.

\section{Material and Methods}

In order to establish the spider fauna, spider

\section{Author's Address}

Department of Zoology, Govt.Vidarbha Institute of Science and Humanities, Amravati, (M.S.)

Email: ujjwaladeshmukh@rediffmail.com specimens were collected during 2009. Collection of spiders was done as per need to identify; repetition of collection of specimens was avoided. Spiders were collected from branches, leaves, flowers, on the ground and under the stones and grasses by stroking, using insect net, pitfall trap, bottle, aspirator and pans. The specimens were put in to $70 \%$ alcohol, labeled and identified according to Tikader (1963). A short overview of genus Stegodyphus with one new species has been illustrated here.

\section{Stegodyphus semadohensis sp. nov. Female}

General characters: Cephalothorax dark brown, abdomen light yellowish green and legs pale yellow with dark brownish bands. Total length $20.0 \mathrm{~mm}$, carapace $7.0 \mathrm{~mm}$ long, $5.0 \mathrm{~mm}$ wide; abdomen 14.0 $\mathrm{mm}$ long, $\mathrm{mm} 11.0 \mathrm{~mm}$ wide.

Cephalothorax: Longer than wide, broad in front, clothed with dark brown pubescence and spine like black and white hairs. Cephalic region elevated, eyes are eight arranged in two rows, anterior row of eyes slightly pro-curved, median slightly larger than laterals, close to each other than to laterals situated at the tubercles. Posterior row of eyes strongly re-curved, medians larger than the laterals, 
median ocular quad larger than wide, and wider behind than in front. Eye position as in Fig. 1(b). Labium and maxillae larger than wide, dark brown in color, clothed with spine like hairs. Labium anteriorly shows small spines, anterior end of maxillae provided with scapulae. Chelicerae vertical, long and strong, clothed with white pubescence, inner and outer margins are provided with spine like hairs. Sternum elliptical narrowing behind, clothed with white pubescence and some black hairs. Legs relatively short and stout clothed with hairs and spines. Femur of all legs provided with two black patches. Legs are pale yellow with dark brown bands. $1^{\text {st }}$ leg longer and broader than other.

\section{Leg formula- 1,4,2,3.}

Abdomen: Longer than wide, broader just behind the middle, narrowing behind clothed with white pubescence. Mid-dorsally provided with three pairs of reddish spots. Ventral side slightly lighter than dorsal, clothed with black pubescence midventrally provided with three pairs of round, light reddish spots in a row.

Epigyne as in Fig.1(c), internal genitalia as in Fig. 1(d).

Type Specimen: Holotype female preserved in $70 \%$ alcohol

Type Locality: India, Maharashtra, Semadoh village Amravati Dist. Coll. U.S.Deshmukh, 12.XI 2009.

Habitat: Dry deciduous forests.

Stegodyphus semadohensis sp. nov.

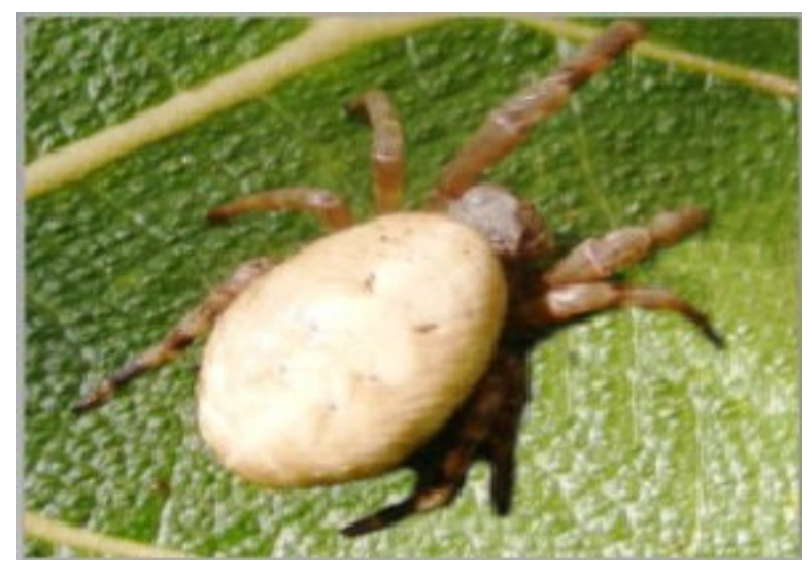

Fig. 1(a) Stegodyphus semadohensis sp. nov. (female)

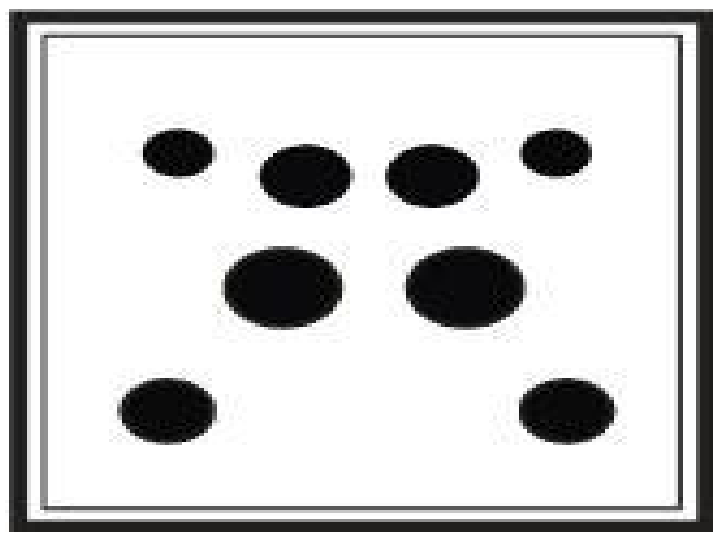

Fig.1(b) Eye position

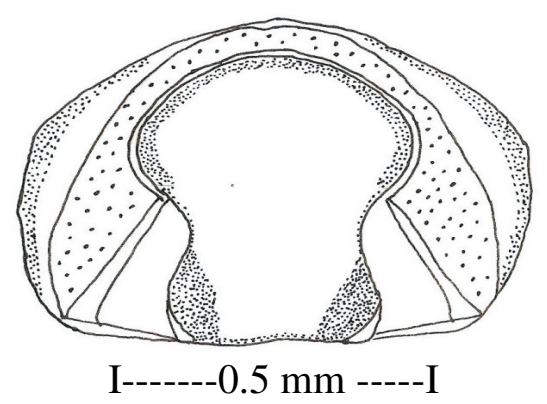

Fig. 1(c) epygine

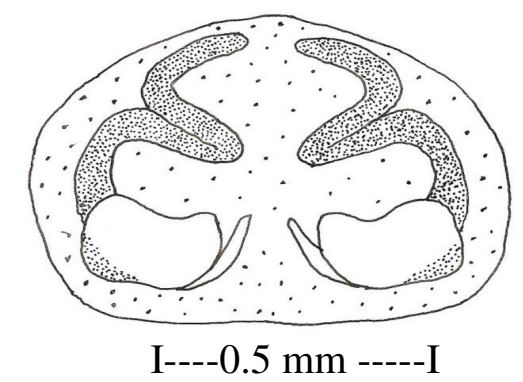

Fig. 1(d) internal genitalia

\section{Results and Discussion}

Stegodyphus semadohensis resembles Stegodyphus mirandus Pocock but differs from it as follows: (i) Cephalothorax dark brown clothed with white and black pubescence but in $S$. mirandus cephalothorax is black, (ii) Abdomen light yellowish green, mid-dorsally provided with three pairs of reddish spots but in S. mirandus abdomen bronze black dorsally with rich golden red at the sides and below, (iii) Femur of all legs provided 
with two black bands but in $S$. mirandus legs are intentionally employed as agents in the biological blackish, (iv) Epigyne and internal genitalia also control for agricultural or garden pests. structurally different.

\section{Conclusion}

As one species have been reported from Satpuda, district Amravati, (Maharashtra State), it is estimated that more species of the genus Stegodyphus and other genera of the family Eresidae may occur in India if thoroughly surveyed. Spiders are predators of pests like aphids, plant bugs, leafhoppers, flies etc. Spiders can be

\section{References}

Gajbe, U.A. 2007. Fauna of Madhya Pradesh (including Chhattisgarh) State fauna series, 15(I): 419-540.

Pocock, R. I. 1900. The fauna of British India, Arachnida: 1227.

Tikader, B. K. 1963. Studies on the spider fauna of Maharashtra and Mysore States. J. Uni. Poona Sci. \& Tech 23: 29-54. 